\section{Strong Electrostatic Adsorption}

${ }^{\star}$ Graphical Abstract

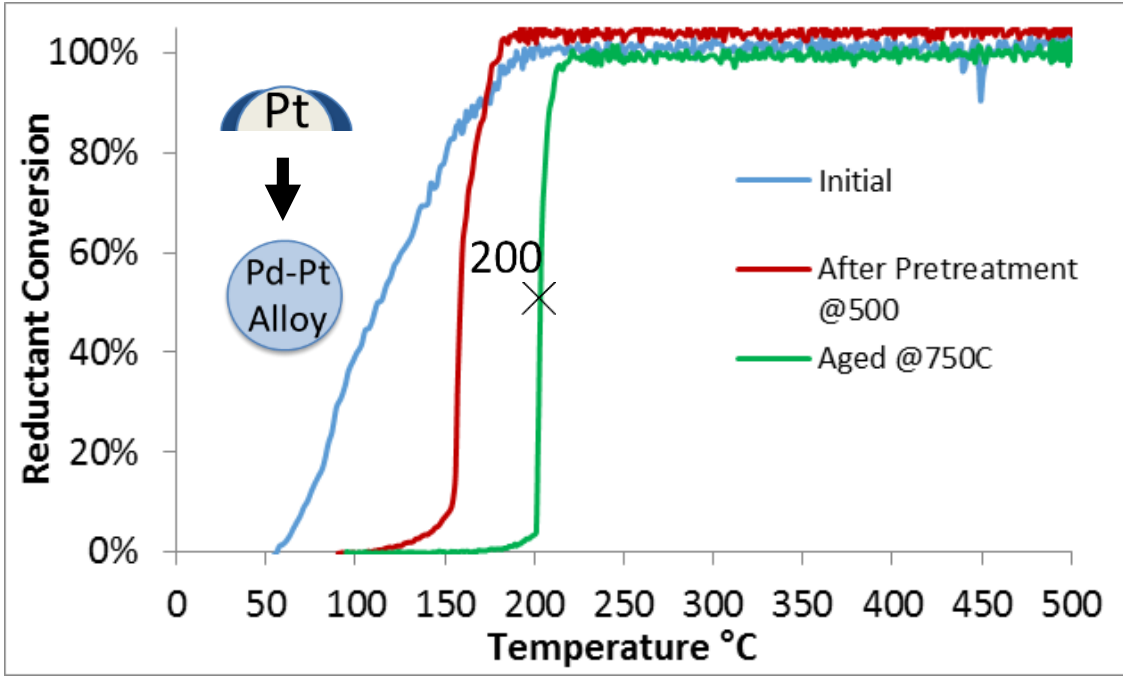

\section{co-Dry Impregnation}

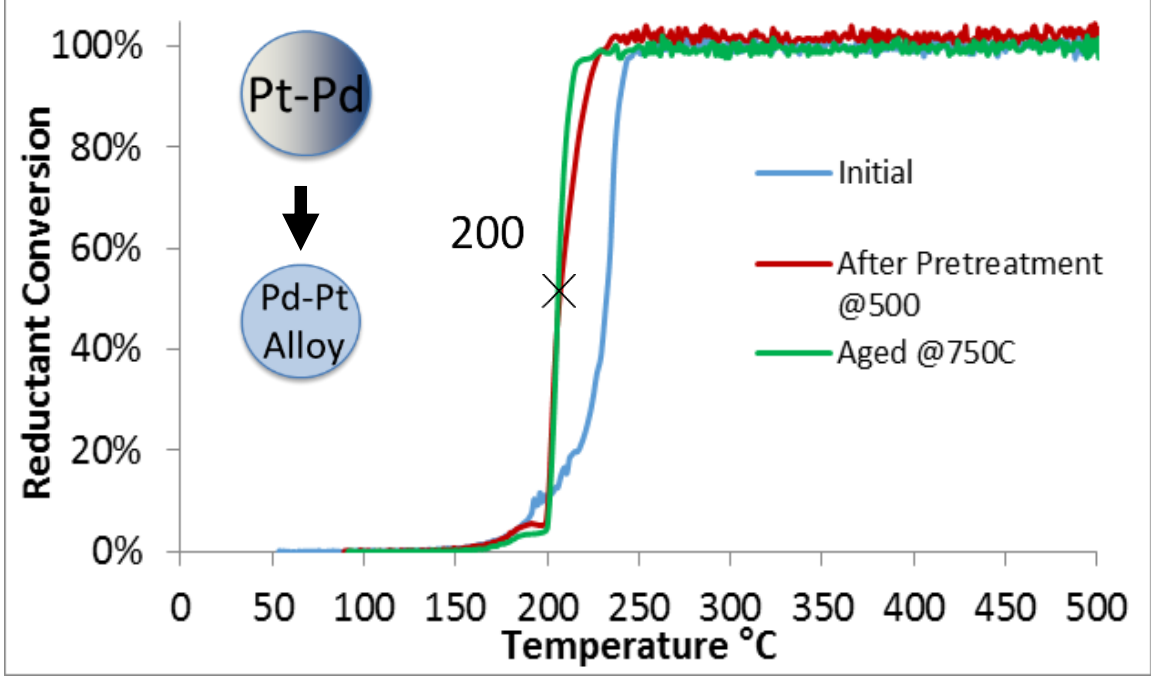




\title{
The Catalytic Behavior of Precisely Synthesized Pt-Pd Bimetallic Catalysts for Use as Diesel Oxidation Catalysts
}

\author{
Andrew P. Wong ${ }^{\mathrm{b}}$, Eleni A. Kyriakidou ${ }^{\mathrm{a}}$, Todd J. Toops ${ }^{\mathrm{a}}$, and John R. Regalbuto ${ }^{\mathrm{b}}$ * \\ ${ }^{a}$ FEERC, Oak Ridge National Laboratory, Knoxville, TN 37932 \\ ${ }^{b}$ Department of Chemical Engineering, University of South Carolina, Columbia, SC \\ 29208, USA
}

\footnotetext{
*Corresponding author; Tel.: 803 7775501; regalbuj@cec.sc.edu
} 


\begin{abstract}
The demands of stricter diesel engine emission regulations have created challenges for current exhaust systems. With advances in low-temperature internal combustion engines and their operations, advances must also be made in vehicle exhaust catalysts. Most current diesel oxidation catalysts use heavy amounts of precious group metals (PGMs) for hydrocarbon (HC), $\mathrm{CO}$, and NO oxidation. These catalysts are expensive and are most often synthesized with poor bimetallic interaction and dispersion. The goal of this work was to study the effect of aging on diesel emission abatement of Pt-Pd bimetallic nanoparticles precisely prepared with different morphologies: well dispersed core-shell versus well dispersed homogeneously alloyed versus poorly dispersed, poorly alloyed particles. Alumina and silica supports were studied. Particle morphology and dispersion were analyzed before and after hydrothermal treatments by XRD, EDX, and STEM. Reactivity as a function of aging was measured in simulated diesel engine exhaust.

While carefully controlled bimetallic catalyst nanoparticle structure has a profound influence on initial or low temperature catalytic activity, the differences in behavior disappear with higher temperature aging as thermodynamic equilibrium is achieved. The metallic character of Pt-rich alumina-supported catalysts is such that behavior rather closely follows the Pt-Pd metal phase diagram. Nanoparticles disparately composed as well-dispersed core-shell (via seq-SEA), well-dispersed homogeneously alloyed (via co-SEA), and poorly dispersed, poorly alloyed (via co-DI) end up as well alloyed, large particles of almost the same size and activity. With Pd-rich systems, the oxidation of Pd also figures into the equilibrium, such that Pd-rich oxide phases appear in the high temperature forms along with alloyed metal cores. The small differences in activity after high temperature aging can be attributed to the synthesis methods, sequential SEA and co-DI which give rise, after aging, to a bimetallic surface enriched in $\mathrm{Pd}$.
\end{abstract}

Keywords: Strong electrostatic adsorption; bimetallic; Pt-Pd; Pt; Pd; diesel oxidation catalyst; $\mathrm{NO}$ 


\section{Introduction}

Diesel oxidation catalysts (DOCs) are a key part of a current diesel exhaust systems along with diesel particulate filters and selective catalytic reduction catalysts [1]. Current diesel oxidation catalysts for the treatment of hydrocarbons and NO are often heavy with precious group metals which makes them rather expensive. Pt is usually included in the DOC because NO oxidation is most active over Pt [2-5]. Pt-only DOCs usually start with high initial activity for both HC and NO but are quickly deactivated after hydrothermal treatments. The primary cause for this loss of activity is due to Pt particle size growth and the loss of Pt dispersion due to high temperatures $[3,5-11]$. However, other catalyst deactivation mechanisms also contribute to activity loss through support sintering, metal particle encapsulation, catalyst poisoning, and phase transformations [9, 12-15].

Attempts to reduce the amount of Pt in current DOCs have been made by the addition of a second metal or modifying the support [15-20]. Modifications include the addition of rare earth metals of $\mathrm{BaO}, \mathrm{La}$, or other oxygen storage compound in order to improve the activity and stability of the catalyst. Other metals studied for oxidation catalysts include combinations of $\mathrm{Au}$, $\mathrm{Co}, \mathrm{Ni}$, and Pd on mixed oxide supports [21]. Bimetallic systems of Pt and Pd have been studied extensively and have been found to be promising DOCs for $\mathrm{HC}, \mathrm{CO}$, and $\mathrm{NOx}$ when compared to Pt-only catalysts $[2,3,5-8,17]$.

The Pt-Pd ratio has been found to be an important aspect of DOCs optimization for HCs and NO $[2,3,6]$. The dilution of Pt by a second metal not only reduces the cost of the DOC, but Pt-Pd bimetallic catalysts are often found to be more hydrothermally stable than Pt-only catalysts $[2,3,5-7,17]$. These Pt-Pd bimetallic catalysts retain their dispersion and activity. However, the surface composition and particle morphology of these bimetallic catalysts often reconstruct after hydrothermal treatments. Many suggest that a surface enrichment of PdO occurs in an oxidative environment for Pd bimetallic catalysts [5, 11, 21-25]. Most of these catalysts studied were synthesized by a simple co-impregnation method, which often lacks high metal dispersion and homogenous alloying.

The goal of this present study was to examine the behavior of bimetallic nanoparticles synthesized with precise compositions and morphologies, and their stability upon aging in a model diesel exhaust stream. We have reported the syntheses of these catalysts in a separate paper [26]: highly-dispersed core-shell and alloyed Pt-Pd bimetallic catalysts as well as single- 
metals supported on alumina and silica. The bimetallic core-shell structures were synthesized via sequential strong electrostatic adsorption (seq-SEA), and the bimetallic alloys were synthesized by simultaneous, or co-SEA. These are compared to traditional co-impregnated formulations. Catalyst performance was measured in a simulated diesel exhaust stream upon several aging conditions. Characterization by XRD, STEM, and EDX of fresh and aged samples provided insight to Pt-Pd particle morphology and size after a simulated catalyst lifetime.

\section{Experimental}

\section{Catalyst Preparation}

Detailed synthesis and characterization of the fresh catalysts can be found in [26]. Strong electrostatic adsorption (SEA) requires adjusting the initial $\mathrm{pH}$ of the solution to charge the support surface. Silica (Evonik Aerosil-300, BET area: $330 \mathrm{~m}^{2} / \mathrm{g}$ ) and commercial $\gamma$-alumina (UOP VGL-25, BET area: $277 \mathrm{~m}^{2} / \mathrm{g}$ ) catalysts were previously prepared by SEA [26]. Cationic precursors of tetraammine platinum(II) chloride (PTA) or tetraammine palladium(II) chloride (PdTA) were used over the low $\mathrm{PZC} \mathrm{SiO}_{2}$ for the noble metal cores. Anionic precursors of chloroplatinic acid (CPA) or sodium tetrachloropalladium (PdTC) were used as over $\mathrm{Al}_{2} \mathrm{O}_{3}$ for the noble metal cores. Sequential-SEA (seq-SEA) cycles on $\mathrm{SiO}_{2}(\mathrm{CPA})$ and $\mathrm{Al}_{2} \mathrm{O}_{3}(\mathrm{PTA}$ or PdTA) were used to form core-shell structures, and co-SEA syntheses were used to form homogenous alloys over $\mathrm{SiO}_{2}$ (PTA and PdTA) and $\mathrm{Al}_{2} \mathrm{O}_{3}$ (CPA and PdTC). CPA and PdTC were used for the dry impregnation catalysts. $\mathrm{HCl}$ and $\mathrm{NaOH}$ were used to adjust the $\mathrm{pH}$ values for all solutions except for PdTC. PdTC was adjusted with $\mathrm{HNO}_{3}$ and $\mathrm{NH}_{4} \mathrm{OH}$.

All fresh SEA catalysts were highly dispersed and in either core-shell or homogeneously alloyed morphologies. Dry Impregnation (DI) catalysts were synthesized using typical coimpregnation or incipient wetness. All catalysts were reduced (without calcination) in $10 \% \mathrm{H}_{2}$ balanced He prior to the initial evaluation, at conditions $\left(150-210^{\circ} \mathrm{C}\right)$ identified by temperature programmed reduction [26]. The series of catalysts of different supports, Pt and/or Pd weight loadings and morphologies are shown in Table 1. Metal weight loadings of SEA-derived catalysts were typically set by the monolayer adsorption capacity of metal precursors on the respective supports. In some cases, repeated cycles of SEA were employed to increase metal loadings so as to render metal loadings sufficiently high for characterization by STEM, X-ray maps, and XRD. While this meant that the atomic composition of metals could not be kept 
identical from case to case (Pt rich alumina, Pd rich alumina, and Pd rich silica catalysts), comparisons can be made directly between samples of a series, and cross comparisons can be made with due consideration of metal loading and particle size.

\section{Catalytic Activity}

Catalytic activity tests were performed at Oak Ridge National Lab at the Fuels, Engines and Emissions Research Center (FEERC). A model diesel exhaust feed consisting of 1500 ppm $\mathrm{CO}, 87 \mathrm{ppm} \mathrm{C}_{3} \mathrm{H}_{6}, 87 \mathrm{ppm}_{3} \mathrm{H}_{8}, 300 \mathrm{ppm} \mathrm{NO}, 10 \% \mathrm{O}_{2}, 5 \% \mathrm{H}_{2} \mathrm{O}$ in Ar was used to evaluate the catalysts. A flow reactor with $35 \mathrm{mg}$ of catalyst and a GHSV of $360,000 \mathrm{hr}^{-1}$ was heated to $500^{\circ} \mathrm{C}$ as a pretreatment, $750^{\circ} \mathrm{C}$ and held for 8 hours as a hydrothermal aging treatment, and heated again to $500^{\circ} \mathrm{C}$ for evaluation after hydrothermal aging. Figure 1 shows a temperature profile for the experiment. Gas concentrations were determined using a SRS RGA 100 mass spectrometer and Eco Physics CLD 822 NOx chemiluminescence.

\section{Hydrothermal Aging}

A separate hydrothermal aging procedure was performed in a benchtop flow reactor for catalyst characterization. These catalysts were treated at $500^{\circ} \mathrm{C}$ for 2 hours or $750^{\circ} \mathrm{C}$ for 8 hours in a feed of $1 \% \mathrm{CO}, 10 \% \mathrm{H}_{2} \mathrm{O}$, and $10 \% \mathrm{O}_{2}$ in $\mathrm{N}_{2}$.

\section{Post-Aging Characterization}

Aged catalysts were characterized by x-ray diffraction (XRD) using a Rigaku MiniFlex II equipped with a high sensitivity $\mathrm{D} /$ tex Ultra $\mathrm{Si}$ slit detector with a nanoparticle size detection limit of about $1 \mathrm{~nm}$ [27]. Patterns were recorded from 10-80 $2 \theta$ using a $\mathrm{Cu}-\mathrm{K} \alpha$ radiation source $(\lambda=1.5406 \AA$ ) operated at $30 \mathrm{~mA}$ and $15 \mathrm{kV}$. The Scherrer equation was used to determine the bulk particle size, and peak location was used to determine oxide formation.

The electron microscopy images were taken at the University of Illinois at Chicago. A JEM-ARM200CF electron microscope capable of elemental mapping was used for determining particle morphology and size. This probe aberration corrected $200 \mathrm{kV}$ microscope operated with a cold field emission source of $0.35 \mathrm{eV}$ energy resolution. The microscope was equipped with a high steradian Oxford Instruments X-Max TLE $100 \mathrm{~mm}^{2}$ detector which permits elemental maps of nanoparticles even with insulating alumina and silica supports.

\section{Results}




\section{Fresh Catalyst Characterization}

Characterization of the fresh catalysts from [26] is summarized in the left hand side of Table 1. Additional STEM characterization of the fresh single metal Pt/alumina, Pd/alumina, and $\mathrm{Pd} /$ silica catalysts synthesized with SEA, shown in later Figures 4a, 5a, and 6a, respectively gave STEM-determined sizes of 1.9, 0.8, and $1.6 \mathrm{~nm}$ which agree with the prior XRD undetectability. The core-shell catalysts prepared by sequential SEA (Pd@Pt or Pt@Pd), confirmed to have that morphology in the previous work [26] were also small in size. The Pd shell on alumina supported Pt were $3.0 \mathrm{~nm}$ in diameter, the Pt shells on alumina supported Pd were $2 \mathrm{~nm}$ in diameter, and the Pt shells on silica supported Pd were $2 \mathrm{~nm}$ in diameter. Simultaneous SEA (or co-SEA) Pt/Pd nanoparticles were $1.7 \mathrm{~nm}$ on alumina, and $1.1 \mathrm{~nm}$ on silica. SEA gives the ability to make highly dispersed single metal, or bimetallic homogeneous alloyed or core-shell particles. The co-DI versions of each catalyst were initially poorly alloyed and agglomerated.

\section{Initial and Aged Catalytic Activity}

The activity of the fresh and aged catalysts was determined using light-off curves of the total reductants in the stream; $\mathrm{CO}_{2}$ was the only carbon product. The light-off curves follow the characteristic shape of $\mathrm{CO}$ light-off, where $\mathrm{CO}$ inhibition prevents $\mathrm{O}_{2}$ from reaching the catalytic surface until a certain temperature, followed by a steep rise in conversion aided by the exothermal oxidation of CO.

The light-off curves of the reductants for the Pt-rich alumina catalysts are shown in Figures 2a-d. Starting with the Pt-only, SEA-prepared catalyst designated as 6.2Pt SEA (Figure $2 \mathrm{a}$ ), the initial activity was greatest with a $\mathrm{T}_{50}$ of $190^{\circ} \mathrm{C}$. A pretreatment at $500^{\circ} \mathrm{C}$ for 2 hours did not significantly affect the $\mathrm{T}_{50}$; however, some of the low temperature activity was lost. After aging this catalyst at $750^{\circ} \mathrm{C}$ for 8 hours, a large decrease in activity was observed giving a $\mathrm{T}_{50}$ of $264^{\circ} \mathrm{C}$.

Light-off curves after adding a Pd-shell to the Pt catalyst (Pt@Pd) can be observed in Figure $2 \mathrm{~b}$ for the $6.0 \mathrm{Pt} / 1.28 \mathrm{Pd}$ seq-SEA catalyst. The initial activity was again greatest with a $\mathrm{T}_{50}$ of $115^{\circ} \mathrm{C}$; large decreases in activity followed pretreatment at $500^{\circ} \mathrm{C}$ and aging at $750^{\circ} \mathrm{C}$. Notable low-temperature activity was observed for the fresh catalyst, indicated by the broad 
light-off curve of the initial ramp which began at just over $50^{\circ} \mathrm{C}$, but this disappeared after pretreatment. The $\mathrm{T}_{50}$ of the pretreated and aged catalyst rose to $155^{\circ}$ and $200^{\circ} \mathrm{C}$, respectively.

Results for the initially poorly dispersed, poorly alloyed Pt/Pd catalyst prepared by co-DI, (6.0Pt/1.28Pd DI) are shown in Figure 2c. For this sample, the pretreatment and aging actually improved the performance somewhat, such that the activity of the aged sample was as good as the aged core-shell sample of Figure $2 \mathrm{~b}$, with a $\mathrm{T}_{50}$ of $200^{\circ} \mathrm{C}$. Results of the initially well dispersed, homogeneous alloyed $\mathrm{Pt} / \mathrm{Pd}$ catalyst via co-SEA ( 5.3Pt/1.58Pd co-SEA) are shown in Figure $2 \mathrm{~d}$. This sample displayed the most stable performance of all catalysts, with the $\mathrm{T}_{50}$ decreasing about $10^{\circ} \mathrm{C}$ to $227^{\circ} \mathrm{C}$ after aging.

The palladium-rich, alumina-supported catalysts are shown in Figures 2e-g. The light-off curve for the well dispersed Pd-only catalyst (2.0Pd SEA) is shown in Figure 2e. Initial activity was lowest while the activity after pretreatment was highest. The $\mathrm{T}_{50}$ of the aged sample slightly rose to $227^{\circ} \mathrm{C}$.

The addition of a Pt shell to the Pd catalyst to form a Pd@Pt morphology (Figure 2f) greatly improved the initial activity of the catalyst, but the activity decreased upon pretreatment and then increased after aging by $5^{\circ} \mathrm{C}$ to a $\mathrm{T}_{50}$ of $233^{\circ} \mathrm{C}$, a few degrees higher than the Pd-only catalyst. Results of the analog DI catalyst on alumina (2.0Pd/0.33Pt DI) are shown in Figure $2 \mathrm{~g}$. Similar to the Pd-only catalyst (Figure $2 \mathrm{e}$ ), initial activity was very low $\left(\mathrm{T}_{50}\right.$ about $325^{\circ} \mathrm{C}$ ), and pretreating and aging the catalyst ultimately improved the $\mathrm{T}_{50}$ to $242^{\circ} \mathrm{C}$.

Finally, results of the palladium-rich series of catalysts on silica are given in Figure 3; the Pd-only catalyst is shown in Figure 3a. Unlike the Pd-only alumina catalyst which exhibited low initial activity $\left(\mathrm{T}_{50}=285^{\circ} \mathrm{C}\right)$, the initial activity was high $\left(\mathrm{T}_{50}=125^{\circ} \mathrm{C}\right)$ for the Pd-only silica catalyst. Activity decreased significantly with pretreatment and aging, such that the $\mathrm{T}_{50}$ for the aged catalyst was $252^{\circ} \mathrm{C}$. Light-off curves from the addition of a Pt-shell to the Pd core (Pd@Pt, 4.0Pd/0.44Pt seq-SEA) are shown in Figure 3b. Adding Pt as a shell lowered the initial activity but reduced the deactivation from pretreatment and aging such that the aged $\mathrm{T}_{50}$ was of $233^{\circ} \mathrm{C}$, about 20 degrees higher than the Pd-only catalyst in Figure 3a.

Results of the initially poorly alloyed, poorly dispersed co-DI catalyst (4.0Pd/0.44Pt DI) are shown in Figure 3c. Initial activity is once again the lowest and activity increases with additional pretreatment and aging, ending with a series-best $\mathrm{T}_{50}$ of $218^{\circ} \mathrm{C}$. The initially well dispersed co-SEA catalyst (3.2Pd/0.56Pt co-SEA), shown in Figure 3d, yielded high initial 
activity but was much less stable than its alumina counterpart (Figure $2 \mathrm{~d}$ ), as the $\mathrm{T}_{50}$ increased from pretreatment to aging and ended at $239^{\circ} \mathrm{C}$.

\section{Aged Characterization}

XRD was used to determine the sintering and oxidation which occurred during pretreatment and aging. STEM images and elemental maps provided a second estimate of particle size and revealed the structures of bimetallic nanoparticles. The number average size is reported for STEM as the small number of particles imaged and wide particle size distribution gave artificially high volume averages. A comparison between the STEM and XRD particle sizes as well as cartoons of the aging process is included in right hand side of Table 1.

\section{$\underline{\text { Alumina Supported Catalysts }}$}

Characterization of the series of Pt-rich alumina catalyst is given in Figure 4. The $6.2 \mathrm{Pt}$ SEA (Figure 4a) initially started with small (XRD transparent, sub-2 $\mathrm{nm}$ ) particles which sintered to a XRD particle size of 5 and $15 \mathrm{~nm}$ after pretreating and aging, respectively, as calculated from the sharpened fcc Pt peaks at (111), (200), and (220) at $40^{\circ}, 46^{\circ}$, and $68^{\circ} 2 \theta$. Size estimates of the aged and fresh Pt-only catalyst in Figure 4a are in reasonable agreement with the STEM size estimates. The Pt@Pd core-shell 6.0Pt/1.28Pd seq-SEA catalyst is characterized before and after aging in Figure 4b. The particles initially were $3 \mathrm{~nm}$ [26] and sintered to 9 and $20 \mathrm{~nm}$, for the $500^{\circ} \mathrm{C}$ and $750^{\circ} \mathrm{C}$ aged samples. Formation of a small amount of $\mathrm{PdO}\left((101)\right.$ peak at $\left.33.9^{\circ} 2 \theta\right)$ was also observed after $500^{\circ} \mathrm{C}$ pretreatment, but the oxide disappeared after the high temperature aging step. (The rise in the peak at $32^{\circ} 2 \theta$ is from the sintering of the alumina phase, seen in this and all other peaks of the aged alumina patterns in Figures 4 and 5.) Micrographs in Figure $4 \mathrm{~b}$ for the aged sample suggest a slightly larger particle size at $26 \mathrm{~nm}$. Elemental maps, of which a representative image is given in Figure 4b, revealed that the Pd initially in a shell [26] dissolved mostly into the Pt core, although a small percentage of images indicated the retention of some Pd surface enrichment.

Characterization of the 6.0Pt/1.28Pd DI catalyst is given in Figure 4c. The initial particles were agglomerated and poorly alloyed [26]. After pretreating the DI catalyst at $500^{\circ} \mathrm{C}$, a crystalline peak for $\mathrm{PdO}$ was observed similar to the co-SEA catalyst at $500^{\circ} \mathrm{C}$, and the metallic particle size was around $14 \mathrm{~nm}$. Aging at $750^{\circ} \mathrm{C}$ again decomposed the oxide and sintered the particles to $24 \mathrm{~nm}$. Representative STEM images and elemental maps for the aged DI sample 
(Figure 4c) revealed that the large nanoparticles were virtually all homogeneously alloyed. The STEM size estimate at $30 \mathrm{~nm}$, is in reasonable agreement with XRD.

The addition of Pd to the Pt catalyst via co-SEA produced alloyed particles $<2 \mathrm{~nm}$ confirmed by XRD and STEM [26]. Metallic peaks are noticeable in Figure 4d for the pretreated $500^{\circ} \mathrm{C}$ and aged $750^{\circ} \mathrm{C}$ samples, with the higher temperature aged sample having sharper XRD peaks correlating to a particle size of $13 \mathrm{~nm}$. Pd or Pd-rich oxide formation was observed in the $500^{\circ} \mathrm{C}$ aged sample at $33.9^{\circ}, 41.9^{\circ}$, and $54.8^{\circ} 2 \theta$ for the $(101),(110)$, and $(112) /(211)$ planes. No $\mathrm{PdO}$ peaks were observed for the sample aged at $750^{\circ} \mathrm{C}$, suggesting that decomposition of $\mathrm{PdO}$ occurs at elevated temperatures. STEM images and elemental maps were taken after aging at $750^{\circ} \mathrm{C}$ (representative images shown in Figure 4d). The STEM particle size of $11 \mathrm{~nm}$ agrees reasonably with the XRD size of $13 \mathrm{~nm}$. Elemental maps (typical map in Figure 4d) indicated homogeneous alloying of the high temperature sintered particles.

Characterization of the Pd-rich alumina series is shown in Figure 5. Initially and after $500^{\circ} \mathrm{C}$ pretreatment of the $2.0 \mathrm{Pd}$ SEA Pd-only catalyst, the Pd particles were too small to be detected by XRD (Figure 5a). STEM images revealed a fresh particle size of $0.8 \mathrm{~nm}$. After $750^{\circ} \mathrm{C}$ aging, only peaks from $\mathrm{PdO}$ were observed at $33.6^{\circ}, 33.9^{\circ}, 41.9^{\circ}, 54.8^{\circ}$, and $71.6^{\circ} 2 \theta$. The peak breadths indicated an XRD particle size of $12 \mathrm{~nm}$. This is in reasonable agreement with the STEM size estimate of $9.6 \mathrm{~nm}$. Characterization for the Pt shell on Pd by seq-SEA is given in Figure 5b. Particle size was initially around $2 \mathrm{~nm}$; aging the sample at $500^{\circ} \mathrm{C}$ gave oxide particles of about $7 \mathrm{~nm}$ in diameter. Further aging to $750^{\circ}$ increased the size of the oxide phase to $9 \mathrm{~nm}$ and created a metallic (111) peak around $11 \mathrm{~nm}$ in size. STEM images in Figure $5 \mathrm{~b}$ indicated an average particle size of $7 \mathrm{~nm}$, in rough agreement with the XRD particle size. Representative elemental maps of this catalyst (Figure 5b, right) revealed significant fractions of both alloyed and Pd surface-enriched particles.

Characterization of the 2.0Pd/0.33Pt DI catalyst is given in Figure 5c. Particles initially started on the small side due to the CEDI (charge enhanced dry impregnation) effect [26], but after aging at either 500 or $750^{\circ} \mathrm{C}$, both sharp metallic and oxide XRD peaks existed. These peaks were the sharpest in the Pd-rich alumina catalyst series and corresponded to an aged at $750^{\circ} \mathrm{C}$ XRD particle size of 17 and $25 \mathrm{~nm}$ for the oxide and metallic peaks, respectively. STEM and elemental maps in Figure 5c show agglomerated particles and inhomogeneous morphology of the Pt-Pd. Significant phase separation occurred, with Pd being enriched on the surface. The 
large discrepancy of STEM and XRD can be explained by the presence of facets in the large agglomerates imaged in STEM.

\section{Silica Supported Catalysts}

Characterization of the Pd-rich silica-supported catalysts is shown in Figure 6. XRD patterns for the Pd-only 4.0Pd SEA catalyst is shown in Figure 6a. Initially too small to be detected, particles of $\mathrm{PdO}$ grew upon aging, to $4 \mathrm{~nm}$ after $500^{\circ} \mathrm{C}$ and to $6 \mathrm{~nm}$ after $750^{\circ} \mathrm{C}$. XRD is in reasonable agreement with STEM, which showed a particle size of $1.6 \mathrm{~nm}$ for the fresh catalyst and $5 \mathrm{~nm}$ for the aged. Results of the seq-SEA-derived Pd@Pt sample are shown in Figure $6 \mathrm{~b}$. Initially metallic particles formed oxides when treated at $500^{\circ} \mathrm{C}$. Further aging to $750^{\circ} \mathrm{C}$ created an addition set of sharp (111), (200), and (220) metallic peaks which indicated a particle size of $24 \mathrm{~nm}$. The oxide particle size after 500 and $750^{\circ} \mathrm{C}$ were 9 and $8 \mathrm{~nm}$, respectively. STEM images in Figure $6 \mathrm{~b}$ show particles homogenously distributed across the silica surface. STEM particle size at $8 \mathrm{~nm}$ agrees with the oxide formation XRD size, but no evidence of the larger metallic particles were observed in the micrographs; this could be due to the small sampling area of STEM. Elemental maps in Figure $6 \mathrm{~b}$ suggest the formation of alloyed particles, although some images indicate a few Pd@Pt core-shell remaining.

Results for the 4.0Pd/0.44Pt DI catalyst are shown in Figure 6c. The initial particle size of this sample had the sharpest XRD peaks, indicating the largest initial particle size. Crystalline peaks at $22^{\circ}$ and $32.2^{\circ} 2 \theta$ in the initial XRD pattern were due to salt $(\mathrm{NaCl})$ left over from the DI preparation. These peaks disappeared at higher temperatures as Pt-Pd metallic and Pd oxide peaks form in both the 500 and $750^{\circ} \mathrm{C}$ aged samples. The XRD particle size for the oxide peaks for the 500 and $750^{\circ} \mathrm{C}$ aged samples are 12 and $14 \mathrm{~nm}$, and the XRD particle size for the metallic peaks are 19 and $34 \mathrm{~nm}$, respectively. The micrographs in Figure 6c showed large particles that averaged $21 \mathrm{~nm}$ in size. Elemental maps for this catalyst showed an enrichment of $\mathrm{PdO}$ on the metal surface; this can also be seen in the Z-contrast images.

An initially homogeneously alloyed catalyst prepared by co-SEA (3.2Pd/0.56Pt co-SEA) is shown in Figure 6d. Similar trends as for the Pd@Pt catalyst were observed. Oxide particle size was $8 \mathrm{~nm}$ for both aging conditions, and sharp metallic peaks indicating $28 \mathrm{~nm}$ were observed in the sample aged at $750^{\circ} \mathrm{C}$. The elemental maps and STEM in Figure 6d indicate large, alloyed particles but also smaller particles about $8 \mathrm{~nm}$ composed entirely of $\mathrm{Pd}$ (as PdO). (The single-pixel spots of color seen in the maps of Figure $6 \mathrm{~d}$ are noise stemming from the 
difficulty of mapping small, individual nanoparticles; no individual atoms were observed in the Z-contrast images.)

\section{Discussion}

A number of factors might account for differences in reactivity brought on by high temperature aging of bimetallic catalysts:

1) Sintering/loss of metal sites

2) Change in degree of alloying; enhanced mixing vs. surface segregation vs. separation of metals

3) Change in the oxidation state of the metal

4) Elimination of residual salts from catalysts prepared by dry impregnation.

As will be discussed below, the first three considerations appear operative in correlating the reactivity data in Figures 2 and 3 with the characterization data in Figures 4-6.

\section{Single Metal Catalysts}

It is helpful to make an initial comparison of the reactivity of variously aged single metal catalysts, $6.2 \mathrm{wt} \% \mathrm{Pt} /$ alumina, $2.0 \mathrm{wt} \% \mathrm{Pd} /$ alumina, and $4.0 \mathrm{wt} \% \mathrm{Pd} / \mathrm{silica}$. The respective activity of these catalysts is seen in Figures 2a, 2e, and 3a, while the characterization is seen in Figure $4 \mathrm{a}, 5 \mathrm{a}$, and $6 \mathrm{a}$.

The reduction in activity of the Pt-only, alumina-supported catalyst (Figure 2a) diminished with pretreatment and aging as would be expected as the particles grow from 1.9 (fresh) to 5 (pretreated) to $15 \mathrm{~nm}$ (aged). Sintering in-situ in the first temperature run-up is likely the cause of the irregularities in the initial light off curve. The large gap in $\mathrm{T}_{50}$ from the pretreated to the aged sample, however, suggests more than sintering. Typical activation energies for this reaction are near $100 \mathrm{~kJ} / \mathrm{mol}[15,28,29]$, for which rates double every $10^{\circ} \mathrm{C}$. An increase in particle size from 5 to $15 \mathrm{~nm}$ would eliminate two thirds of surface sites, or about $15^{\circ} \mathrm{C}$ of activity, but the gap is about $60^{\circ} \mathrm{C}$. A plausible explanation is that the reaction is structure sensitive, with smaller particles being more active. Work by the Ozawa group has found that increased $\mathrm{Pt}$ dispersion aids in $\mathrm{HC}$ and $\mathrm{CO}$ activity; however, they observed a significant support effect when comparing activities over different alumina supports [30, 31]. 
In the case of Pd, highly-dispersed $\mathrm{Pd}$ has been cited to be more active for $\mathrm{CO}$ oxidation than poorly dispersed Pd [32]. The Datye group observed the highest CO activity over atomically dispersed Pd supported on lanthanum modified alumina [33]. Others have claimed the dispersion of the metal has less effect on activity than does Pd oxide formation [34-36]. In the current results, the Pd-only catalysts display an interesting contrast in behavior which contains elements of both size and oxidation effects. The alumina-supported catalyst (Figure 2e) is initially relatively inactive, requiring some sort of activation, while the silica supported catalyst (Figure 3a) is immediately active and deactivates substantially with aging. In the latter case, the large gaps in activity between fresh, pretreated, and aged light off curves is more than can be justified with only sintering. On silica the initial Pd particles size is less than $2 \mathrm{~nm}(\mathrm{Pd}$ is XRD transparent) and sinters to 4 and $6 \mathrm{~nm}$ (Table 1) Pd oxide after pretreatment and aging. The reduction of active area by about half and then again by about $40 \%$ (from 4 to $6 \mathrm{~nm}$ ) is again incommensurate with the large changes in $\mathrm{T}_{50}$ and again suggests a particle size effect with smaller PdO particles having higher inherent activity. Behavior over the different supports can be explained by $\mathrm{PdO}$ and not metallic Pd being the active $\mathrm{Pd}$ species for the oxidation reaction, which is often cited in the literature [18, 34, 35, 37-40], and that silica stabilizes Pd oxides when $\mathrm{Pd}$ exists as very small particles, while alumina does not. The spontaneous oxidation of small Pt particles on silica and alumina has been recently documented [41, 42]. Over alumina, Pd particles do not significantly sinter after the $500^{\circ} \mathrm{C}$ pretreatment (Figure $5 \mathrm{a}$; $\mathrm{Pd}$ phase is still unobservable) so the large increase in activity in Figure 2e can be attributed to the oxidation of metallic Pd nanoparticles. The effect of Pd oxidation state would then best be compared for the initial and pretreated Pd-only catalysts over alumina, which are about the same size $(<1.5 \mathrm{~nm})$. The relatively small decrease in activity from the $500^{\circ} \mathrm{C}$ pretreatment to the $750^{\circ} \mathrm{C}$ aging of about 10 degrees is perhaps more commensurate with a loss of active area due to sintering.

Low initial reactivity and Pd activation occurs in three other cases - all the co-DI prepared samples (Figure 2c, 2g, and 3c). These DI-derived samples all contain Pd particles that are initially large and metallic (XRD patterns of Figs. 5c, 6c, and 7c). Ambient oxidation only happens in the smallest particles $[41,42]$ and so would not occur over the co-DI silica catalyst (Figures 3c and 6c). Also, the activation of the SEA-derived Pd-only catalyst over alumina is just as dramatic as those of the co-DI catalysts, and occurs to the same extent for the tetraammine coordination complex ( $\mathrm{Pd}$ precursor over silica) as for a tetrachloride complex ( $\mathrm{Pd}$ precursor 
over alumina). Thus, it can be suggested that the activation of the co-DI catalysts is mainly caused by the oxidation of $\mathrm{Pd}$ to $\mathrm{PdO}$ and not removal of residual salt.

Once oxidized, $\mathrm{PdO}$ has the highest intrinsic activity on alumina; $2 \mathrm{wt} \%$ catalysts with 12 nm size (Figure 5a and Table 1) show a $\mathrm{T}_{50}$ of $227^{\circ} \mathrm{C}$ versus $4 \mathrm{wt} \% \mathrm{Pd}$ on silica with $6 \mathrm{~nm}$ particles (Figure 6a) which has a $\mathrm{T}_{50}$ after aging of $252^{\circ} \mathrm{C}$; the silica supported $\mathrm{PdO}$ has twice the loading and twice the dispersion, so about 4 times more active sites but is $25^{\circ} \mathrm{C}$ (about 5 times) less active. Pd/alumina is also more active than Pt/alumina, as the $2.0 \mathrm{wt} \% \mathrm{Pd}$ catalysts in Figure 2e with $12 \mathrm{~nm}$ size (Figure 6a and Table 1) have a $\mathrm{T}_{50}\left(227^{\circ} \mathrm{C}\right.$, Figure 2e) lower than that $\left(\mathrm{T}_{50}=\right.$ $264^{\circ} \mathrm{C}$, Figure 2a) of $6.2 \mathrm{wt} \% \mathrm{Pt}$ with $15 \mathrm{~nm}$ particles (Figure 4a, Table 1). The PdO has about $20 \%$ less active area but is $37^{\circ} \mathrm{C}$ more active.

Summary: Single Metal Catalysts:

$\mathrm{PdO}$ is the active $\mathrm{Pd}$ phase and the presence of metallic $\mathrm{Pd}$ in the fresh alumina catalyst causes low initial reactivity. Activity increases as it oxidizes, but decreases as the PdO phase sinters. Unlike over alumina, Pd on silica oxidizes spontaneously and exhibits high fresh activity. The drop off in reactivity over silica with sintering is incommensurate with increasing particle size (loss of active area) and suggests that smaller particles are intrinsically more active. In the aged catalysts, $\mathrm{PdO}$ on alumina is more active per site than $\mathrm{Pt}$ on alumina, and $\mathrm{Pd}$ on alumina has higher intrinsic activity than $\mathrm{Pd}$ on silica.

\section{Pt Rich, Alumina Supported Catalysts}

Reactivity as a function of aging (Figure 2a-d) can now be compared for bimetallic catalysts in which Pd has been added to the Pt-only catalyst in three distinct ways; as a partial outer shell on well dispersed, SEA-derived Pt cores (the 6.2wt\% Pt-only catalyst), as homogeneous, highly initially dispersed alloys via co-SEA, and as more poorly alloyed, larger, agglomerated particles via co-dry impregnation (Figure 4 and Table 1). The co-DI catalyst is seen in Figure $4 \mathrm{c}$ to have initial metal particles of about $10 \mathrm{~nm}$ in size; these are agglomerated and poorly alloyed [26]. The core-shell Pt@Pd catalyst prepared via seq-SEA [26] has initial size of about $3.0 \mathrm{~nm}$ (Figure 4b), while the fresh homogeneously alloyed [26] co-SEA particles are about $1.7 \mathrm{~nm}$ in average size (Figure $4 \mathrm{~d}$ ).

Adding a Pd shell to Pt produced the highest activity of fresh catalysts seen in this study;

light off began at just over $50^{\circ} \mathrm{C}$ (Figure $2 \mathrm{~b}$ ). While this catalyst has a higher metal loading (an 
additional $1.28 \mathrm{wt} \% \mathrm{Pd}$ ) than the Pt-only catalyst, the Pd has selectively adsorbed onto the Pt nanoparticles [26] such that no additional metal surface has been created, but only a bimetallic one. This must be a bimetallic effect as the partially covered surface is much more active than either the fresh activity of the well-dispersed Pt-only (Figure 2a) or PdO-only (Figure 3a) surfaces alone. Activity diminished considerably with pretreatment and aging as the average particle size grew from 3 to 9 and then $20 \mathrm{~nm}$. These Pt-rich particles remain metallic in general (XRD patterns in Figure 4b) but small amounts of $\mathrm{PdO}$ form at the intermediate aging temperature. This is in accord with the Pt-Pd solubility gap in the phase diagram [43]. As the Pd separates from the Pt phase it likely forms a relatively pure (unalloyed) PdO phase. The diagram also indicates that solubility commences at about $770^{\circ} \mathrm{C}$, and in fact the disappearance of the oxide peaks after the high temperature aging appears to bear this out. Unfortunately the lattice parameters of Pt and Pd are too close to identify the composition of the metal phase which reforms at high temperature.

The initially large and poorly alloyed co-DI particles show activation, as mentioned above, which is consistent with the initial presence of separate, large Pd metal particles. The sample also shows $\mathrm{PdO}$ at the intermediate temperature and then, only metal at the highest temperature treatment (Figure 4c), as occurred for the seq-SEA catalyst. STEM images (Figure 4c) reveal that the large particles are in fact well alloyed; thus, the alumina support has not been able to hinder high temperature equilibration to sintered, alloyed bimetallic particles. Another indication of metal-metal-support phase equilibrium is that the high-T aged activity of both catalysts is the same, $\mathrm{T}_{50}=200^{\circ} \mathrm{C}$, at about the same particle size (20 vs. $24 \mathrm{~nm}$ by XRD, 26 vs. $30 \mathrm{~nm}$ by STEM, Table 1).

The behavior of the alumina supported co-SEA catalyst is the most stable of all catalysts, with only a very small increase in $\mathrm{T}_{50}$ (Figure $2 \mathrm{~d}$ ) as the nanoparticles grow from 1.7 to 8 to 13 $\mathrm{nm}$ (Figure 4d and Table 1). XRD characterization is similar to the seq-SEA catalyst with some oxide appearing at the intermediate temperature, which reverts to all metal at the highest temperature. STEM confirms homogeneous alloying at the highest temperature. The aged particles are somewhat smaller $(13 \mathrm{~nm})$ while the activity is substantially lower $\left(\mathrm{T}_{50}=227\right.$ vs. $200^{\circ} \mathrm{C}$ ) than the seq-SEA and co-DI samples. The relatively insensitivity of activity to particle sintering and the low relative reactivity both suggest that the surface composition of the co-SEA catalyst is somewhat different from the other two (seq-SEA and co-DI) high T-aged catalysts. 
While the $\mathrm{Pd} / \mathrm{Pt}$ ratio is a bit higher for the co-SEA sample, that it is more homogeneously alloyed would suggest that its Pd surface concentration is lower than the other two catalysts, leading to a lesser bimetallic surface effect.

Summary: Pt Rich, Alumina Supported Catalysts

Pd shells on Pt/alumina cores prepared by seq-SEA gave the highest initial activity of any catalyst in this study; this can be attributed to a bimetallic surface effect which is different from the fresh surface of homogeneous Pd/Pt alloys prepared by co-SEA. Aging sinters the co-SEA catalyst the least, but its activity is still below the sintered seq-SEA and co-DI catalysts, which may retain a more optimal surface composition higher in $\mathrm{Pd}$. In the best cases, adding $\mathrm{Pd}$ to $\mathrm{Pt}$ improved the activity by lowering the $\mathrm{T}_{50}$ by $64^{\circ} \mathrm{C}$.

\section{Pd Rich, Alumina Supported Catalysts}

Adding Pt as a shell onto Pd cores (Figures 2f) completely changes the nature of the active surface, as initial activity was not suppressed as in the Pd-only and co-DI catalysts (Figures $2 \mathrm{e}$ and $\mathrm{g}$ ). The decrease in activity of the seq-SEA catalyst in Figure $2 \mathrm{f}$ appears to be proportional to the degree of sintering as the particles grow from 2 to 7 (oxide) and then 11/9 (metal/metal oxide) nm (Figure 5 and Table 1). Too small to be observed by XRD when fresh, the oxide phase (Pd or Pd-rich) appears again after intermediate aging but persists after the high temperature aging, likely due to the much higher Pd content. STEM images reveal alloyed particles, some of which appear to be surface enriched in Pd (Figure 5b, presumably PdO from XRD). Thus it appears the surface has undergone extensive reorganization if not a complete inversion in composition. Surface enrichment of $\mathrm{PdO}$ is also suggested from the similar activity of the aged seq-SEA catalyst to the Pd-only catalyst.

The co-DI catalyst maps (Figure 5c) also did not appear to be as homogeneously alloyed as the seq-SEA catalyst or the Pt-rich alumina catalysts. High T-aged activity was poorer than the Pd-only catalyst, probably due to the large particle size (Figure 5c and Table 1).

It is informative to compare the Pd-only $(\mathrm{PdO}) /$ silica catalyst in Figure $2 \mathrm{e}$ with the $\mathrm{Pt}$ rich, $\mathrm{Pt} / \mathrm{Pd}$ co-SEA catalyst of Figure $2 \mathrm{~d}$. Both have the same aged activity $\left(\mathrm{T}_{50}=227^{\circ} \mathrm{C}\right)$ and both have about the same particle size. The weight loading of $\mathrm{Pd}$ is $2.0 \%$, while the total metals in the $\mathrm{Pt}$ rich catalyst are $6.9 \%$. The Pd-only catalyst has perhaps $50 \%$ less active sites but is as active on the whole. On the other hand, the Pt/Pd co-SEA catalyst in Figure $2 \mathrm{~d}$ is not as active as 
the seq-SEA and co-DI Pt-rich catalysts in Figures $2 b$ and 2c. Both of these comparisons are consistent with the discussion in the previous section that to be most active, $\mathrm{Pd}$ must be at the surface of the bimetallic particles.

Summary: Pd Rich, Alumina Supported Catalysts

Adding a Pt shell to Pd/alumina particles eliminated the need for the activation (oxidation) of the Pd particles and gave higher initial activity. However, in aged catalysts, the addition of Pt did not increase activity compared to the Pd-only catalyst.

\section{Pd Rich, Silica Supported Catalysts}

The final case is adding a Pt to silica supported Pd; activity trends are seen in Figure 3 and characterization is shown in Figure 6 and summarized in Table 1. Adding a Pt shell to a Pdcore catalyst greatly retarded the activity of the fresh catalyst (Figures $3 a$ and $b$ ). This is opposite of the behavior over alumina, where addition of $\mathrm{Pt}$ to the alumina supported Pd greatly increased activity (Figure 2f). But that was because the Pd/alumina, even at small size, appears to be metallic and must be oxidized to become active. On silica, the Pd-only catalyst is already oxidized and most active. Adding Pt to it keeps it in a reduced, metallic state after preparation (initial XRD pattern in Figure 6b) and therefore at low activity. With higher temperature treatments the metals can rearrange. A Pd oxide phase once again appears at the intermediate temperature, and like the Pd-rich alumina and the other silica catalysts, persists through high temperature aging. The reduction in activity is commensurate with particle growth from 2 (metal) to 9 (oxide) to 24/8 (metal/oxide) nm. The STEM images revealed virtually all alloyed particles (Figure 6b). As XRD confirms that $\mathrm{Pd}$ is wholly present as $\mathrm{PdO}$, it must be that $\mathrm{Pt}$ is dissolved in the PdO lattice, at least at the intermediate aging temperature where no metal phase appears (500 aged in Figure 6b). More of a metal phase does appear after high temperature aging. Again, unfortunately, the lattice parameters of Pt and Pd are too close to identify the composition of the metal phase.

The co-DI catalyst behaves as the other two co-DI catalysts, with activity improving upon high temperature treatment (Figure 3c) as the particles become more alloyed (Figure 6c). The low initial activity is again associated with large particles of metallic $\mathrm{Pd}$ as seen in the initial XRD pattern of Figure 6c. Intermediate pretreatment generates mostly the oxide phase, which persists, with somewhat more metal, after high temperature aging. The Pd-rich surface layers 
seen in STEM (Figure 6c) should be oxide, per XRD (Figure 6c), and the alloying in this layer is indicated by this catalyst's higher activity, $\mathrm{T}_{50}=218^{\circ} \mathrm{C}$, with larger particles $(34 / 14 \mathrm{~nm}$ metal/oxide), than the pure $\mathrm{PdO}$ catalyst $\left(\mathrm{T}_{50}=252^{\circ} \mathrm{C}\right.$, particle size $\left.6 \mathrm{~nm}\right)$.

The silica-supported, Pd-rich co-SEA-derived nanoparticles show somewhat different behavior than alumina-supported, Pt-rich ones. In the latter case, the Pt-rich particles remained largely metallic and alloyed through treatment. Over silica, a significant fraction of Pd-only particles were evidenced in STEM maps, with another fraction of alloyed particles. The same affinity of the silica surface for Pd that causes small supported Pd particles to oxidize at ambient conditions may also stabilize pure PdO particles as they form, separately from $\mathrm{Pt}$, at the intermediate aging step. The activity of the silica-supported co-SEA sample is not nearly as insensitive to aging as the alumina supported catalyst (Figure 2d), probably because of this separation of components during aging. Ultimately, the three Pt-containing aged catalysts have higher activity than the Pd-only catalyst, even though the bimetallic particles sizes are larger (Table 1). This is yet further evidence that a bimetallic surface enriched in $\mathrm{Pd}$ is the most active catalyst surface.

Summary: Pd Rich, Silica Supported Catalysts

Adding Pt shells to Pd cores on silica diminishes the initial activity due to the presence of $\mathrm{Pt}$, retaining $\mathrm{Pd}$ in the metallic state. The addition of $\mathrm{Pt}$ to $\mathrm{Pd} /$ silica gives higher activity of aged catalysts, unlike over alumina, where the addition of Pt diminished aged activity.

\section{Summary}

While carefully controlled bimetallic catalyst nanoparticle structure has a profound influence on initial or low temperature catalytic activity, the differences in behavior mostly disappear at higher aging temperatures as thermodynamic equilibrium is achieved. The metallic character of Pt-rich alumina-supported catalysts is such that behavior rather closely follows the Pt-Pd metal phase diagram. Nanoparticles as disparately composed as well-dispersed core-shell (via seq-SEA), well-dispersed homogeneously alloyed (via co-SEA), and poorly dispersed, poorly alloyed (via co-DI) end up as well alloyed, large particles of almost the same size and activity. With Pd-rich systems, the oxidation of Pd also figures into the equilibrium, such that Pd-rich oxide phases appear after the high temperature aging along with alloyed metal cores. 
The small differences in activity after aging can be attributed to the synthesis methods, sequential SEA and co-DI which give rise, after aging, to a bimetallic surface enriched in Pd.

From a practical standpoint, the preparation method for catalysts to be pretreated or aged at such high temperatures is relatively inconsequential over typical alumina and silica supports. Further improvements in performance, utilizing these two metals, might focus on support modifications which anchor the nanoparticles against sintering; over these sorts of supports the initial morphology will be more important.

\section{Acknowledgements}

The support of the National Science Foundation, grant CBET-1160023, is gratefully acknowledged. A portion of this research was sponsored by the U.S. Department of Energy, Office of Energy Efficiency and Renewable Energy, Vehicle Technologies Program, the Center of Renewable Fuels (CReF) at the University of South Carolina, and the Nation Science Foundation. The authors wish to express their gratitude to program managers Ken Howden and Gurpreet Singh for their support. This manuscript has been co-authored by UT-Battelle, LLC, under Contract No. DE-AC05-00OR22725 with the U.S. Department of Energy. The authors would also like to thank Dr. Alan Nicholls at UIC for acquisition of STEM images and elemental maps.

\section{References}

[1] M. Shelef, R.W. McCabe, Twenty-five years after introduction of automotive catalysts: what next?, Catalysis today, 62 (2000) 35-50.

[2] G.W. Graham, H.W. Jen, O. Ezekoye, R.J. Kudla, W. Chun, X.Q. Pan, R.W. McCabe, Effect of alloy composition on dispersion stability and catalytic activity for NO oxidation over alumina-supported Pt-Pd catalysts, Catalysis Letters, 116 (2007) 1-8.

[3] M. Kaneeda, H. Iizuka, T. Hiratsuka, N. Shinotsuka, M. Arai, Improvement of thermal stability of NO oxidation Pt/A12O3 catalyst by addition of Pd, Applied Catalysis B: Environmental, 90 (2009) 564-569.

[4] J.-H. Lee, H.H. Kung, Effect of Pt dispersion on the reduction of NO by propene over alumina-supported Pt catalysts under lean-burn conditions, Catalysis letters, 51 (1998) 1-4. 
[5] A. Morlang, U. Neuhausen, K.V. Klementiev, F.W. Schütze, G. Miehe, H. Fuess, E.S. Lox, Bimetallic Pt/Pd diesel oxidation catalysts, Applied Catalysis B: Environmental, 60 (2005) 191-199.

[6] C.H. Kim, M. Schmid, S.J. Schmieg, J. Tan, W. Li, The Effect of Pt-Pd Ratio on Oxidation Catalysts Under Simulated Diesel Exhaust, 1 (2011).

[7] J. Kim, E. Kim, J. Han, H.S. Han, Pt/Pd Bimetallic Catalyst with Improved Activity and Durability for Lean-Burn CNG Engines, SAE International Journal of Fuels and Lubricants, 6 (2013) 651-656.

[8] K. Irani, W.S. Epling, R. Blint, Effect of hydrocarbon species on no oxidation over diesel oxidation catalysts, Applied Catalysis B: Environmental, 92 (2009) 422-428.

[9] C.H. Bartholomew, Mechanisms of catalyst deactivation, Applied Catalysis A: General, 212 (2001) 17-60.

[10] D. Schmitt, H. Fuess, H. Klein, U. Neuhausen, E. Lox, Influence of platinum precursors on the activity of diesel oxidation catalysts. An EXAFS study, Topics in Catalysis, 16 (2001) 355-362.

[11] F. Skoda, M. Astier, G. Pajonk, M. Primet, Effect of thermal ageing in oxidizing or reducing atmosphere on the texture and structure of palladium, copper and palladium-copper on alumina catalysts, Reaction Kinetics and Catalysis Letters, 55 (1995) 101-110.

[12] H. Arai, M. Machida, Thermal stabilization of catalyst supports and their application to high-temperature catalytic combustion, Applied Catalysis A: General, 138 (1996) 161-176.

[13] P. Forzatti, L. Lietti, Catalyst deactivation, Catalysis today, 52 (1999) 165-181.

[14] A.K. Neyestanaki, F. Klingstedt, T. Salmi, D.Y. Murzin, Deactivation of postcombustion catalysts, a review, Fuel, 83 (2004) 395-408.

[15] A. Russell, W.S. Epling, Diesel Oxidation Catalysts, Catalysis Reviews, 53 (2011) 337-423.

[16] F. Haaß, H. Fuess, Structural characterization of automotive catalysts, Advanced Engineering Materials, 7 (2005) 899-913.

[17] M. Skoglundh, L. Löwendahl, J.-E. Otterated, Combinations of platinum and palladium on alumina supports as oxidation catalysts, Applied catalysis, 77 (1991) 9-20.

[18] T. Kolli, Pd/A12O3 - Based Automotive Exhaust Gas Catalysts, (2006).

[19] S. Benard, L. Retailleau, F. Gaillard, P. Vernoux, A. Giroir-Fendler, Supported platinum catalysts for nitrogen oxide sensors, Applied Catalysis B: Environmental, 55 (2005) 11-21.

[20] L. Olsson, E. Fridell, The Influence of Pt Oxide Formation and Pt Dispersion on the Reactions NO $2 \Leftrightarrow \mathrm{NO}+1 / 2 \mathrm{O} 2$ over Pt/Al 2 O 3 and Pt/BaO/Al 2 O 3, Journal of Catalysis, 210 (2002) 340-353.

[21] J.L. Aluha, G. Pattrick, E. van der Lingen, Palladium-Based Catalysts with Improved Sulphur Tolerance for Diesel-Engine Exhaust Systems, Topics in Catalysis, 52 (2009) 1977 1982.

[22] T. Fujikawa, K. Tsuji, H. Mizuguchi, H. Godo, K. Idei, K. Usui, EXAFS characterization of bimetallic $\mathrm{Pt}-\mathrm{Pd} / \mathrm{SiO} 2-\mathrm{Al} 2 \mathrm{O} 3$ catalysts for hydrogenation of aromatics in diesel fuel, Catalysis letters, 63 (1999) 27-33.

[23] P.L. Hansen, A.M. Molenbroek, A.V. Ruban, Alloy formation and surface segregation in zeolite-supported Pt-Pd bimetallic catalysts, The Journal of Physical Chemistry B, 101 (1997) 1861-1868.

[24] M. Chen, L. Schmidt, Morphology and composition of Pt • Pd alloy crystallites on $\mathrm{SiO} 2 \mathrm{in}$ reactive atmospheres, Journal of Catalysis, 56 (1979) 198-218. 
[25] J.H. Sinfelt, CATALYSIS BY ALLOYS AND BIMETALLIC CLUSTERS, Accounts of Chemical Research, 10 (1977) 15-20.

[26] H.-R. Cho, J.R. Regalbuto, The rational synthesis of Pt-Pd bimetallic catalysts by electrostatic adsorption, Catalysis Today, 246 (2015) 143-153.

[27] K. O'Connell, J. Regalbuto, High Sensitivity Silicon Slit Detectors for $1 \mathrm{~nm}$ Powder XRD Size Detection Limit, Catalysis Letters, 145 (2015) 777-783.

[28] C. Depcik, S. Loya, A. Srinivasan, T. Wentworth, S. Stagg-Williams, Adaptive Global Carbon Monoxide Kinetic Mechanism over Platinum/Alumina Catalysts, Catalysts, 3 (2013) 517-542.

[29] S.M. McClure, D.W. Goodman, New insights into catalytic CO oxidation on Pt-group metals at elevated pressures, Chemical Physics Letters, 469 (2009) 1-13.

[30] M. Haneda, M. Sasaki, H. Hamada, M. Ozawa, Platinum-based catalyst for diesel hydrocarbon oxidation, Chinese Journal of Catalysis, 32 (2011) 777-781.

[31] M. Haneda, T. Watanabe, N. Kamiuchi, M. Ozawa, Effect of platinum dispersion on the catalytic activity of Pt/Al 2 O 3 for the oxidation of carbon monoxide and propene, Applied Catalysis B: Environmental, 142 (2013) 8-14.

[32] K.C. Soni, R. Krishna, S.C. Shekar, B. Singh, Catalytic oxidation of carbon monoxide over supported palladium nanoparticles, Applied Nanoscience, (2015) 1-11.

[33] E.J. Peterson, A.T. DeLaRiva, S. Lin, R.S. Johnson, H. Guo, J.T. Miller, J. Hun Kwak, C.H.F. Peden, B. Kiefer, L.F. Allard, F.H. Ribeiro, A.K. Datye, Low-temperature carbon monoxide oxidation catalysed by regenerable atomically dispersed palladium on alumina, Nat Commun, 5 (2014).

[34] Y. Yazawa, H. Yoshida, N. Takagi, S.-i. Komai, A. Satsuma, T. Hattori, Oxidation state of palladium as a factor controlling catalytic activity of $\mathrm{Pd} / \mathrm{SiO} 2-\mathrm{A} 12 \mathrm{O} 3$ in propane combustion, Applied Catalysis B: Environmental, 19 (1998) 261-266.

[35] Y. Yazawa, H. Yoshida, N. Takagi, S.-i. Komai, A. Satsuma, T. Hattori, Acid Strength of Support Materials as a Factor Controlling Oxidation State of Palladium Catalyst for Propane Combustion, Journal of Catalysis, 187 (1999) 15-23.

[36] G.R. Bamwenda, S. Tsubota, T. Nakamura, M. Haruta, The influence of the preparation methods on the catalytic activity of platinum and gold supported on $\mathrm{TiO} 2$ for $\mathrm{CO}$ oxidation, Catalysis Letters, 44 (1997) 83-87.

[37] R.J. Farrauto, J.K. Lampert, M.C. Hobson, E.M. Waterman, Thermal decomposition and reformation of PdO catalysts; support effects, Applied Catalysis B: Environmental, 6 (1995) 263-270.

[38] R.F. Hicks, H. Qi, M.L. Young, R.G. Lee, Structure sensitivity of methane oxidation over platinum and palladium, Journal of Catalysis, 122 (1990) 280-294.

[39] L. Meng, J.-J. Lin, Z.-Y. Pu, L.-F. Luo, A.-P. Jia, W.-X. Huang, M.-F. Luo, J.-Q. Lu, Identification of active sites for $\mathrm{CO}$ and $\mathrm{CH} 4$ oxidation over $\mathrm{PdO} / \mathrm{Ce} 1-\mathrm{x} \mathrm{Pd}$ x O $2-\delta$ catalysts, Applied Catalysis B: Environmental, 119 (2012) 117-122.

[40] Y. Bi, G. Lu, Catalytic CO oxidation over palladium supported NaZSM-5 catalysts, Applied Catalysis B: Environmental, 41 (2003) 279-286.

[41] J.R. Gallagher, T. Li, H. Zhao, J. Liu, Y. Lei, X. Zhang, Y. Ren, J.W. Elam, R.J. Meyer, R.E. Winans, J.T. Miller, In situ diffraction of highly dispersed supported platinum nanoparticles, Catalysis Science \& Technology, 4 (2014) 3053-3063. 
[42] L.K. Ono, J.R. Croy, H. Heinrich, B. Roldan Cuenya, Oxygen Chemisorption, Formation, and Thermal Stability of Pt Oxides on Pt Nanoparticles Supported on SiO2/Si(001): Size Effects, The Journal of Physical Chemistry C, 115 (2011) 16856-16866.

[43] E. Raub, Metals and alloys of the platinum group, Journal of the Less Common Metals, 1 (1959) 3-18. 
Table $1 \mathrm{Al}_{2} \mathrm{O}_{3}$ and $\mathrm{SiO}_{2}$ catalysts

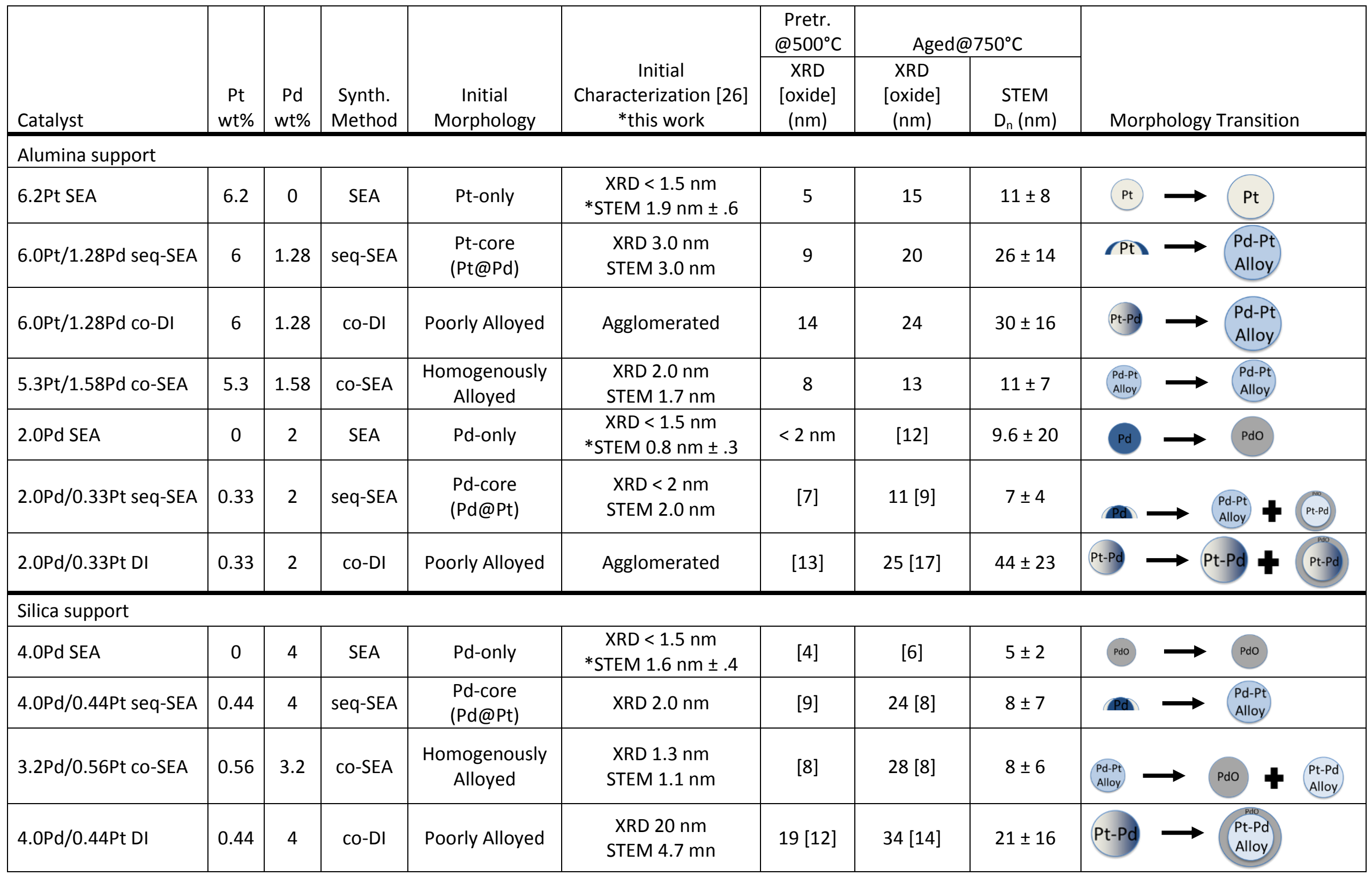




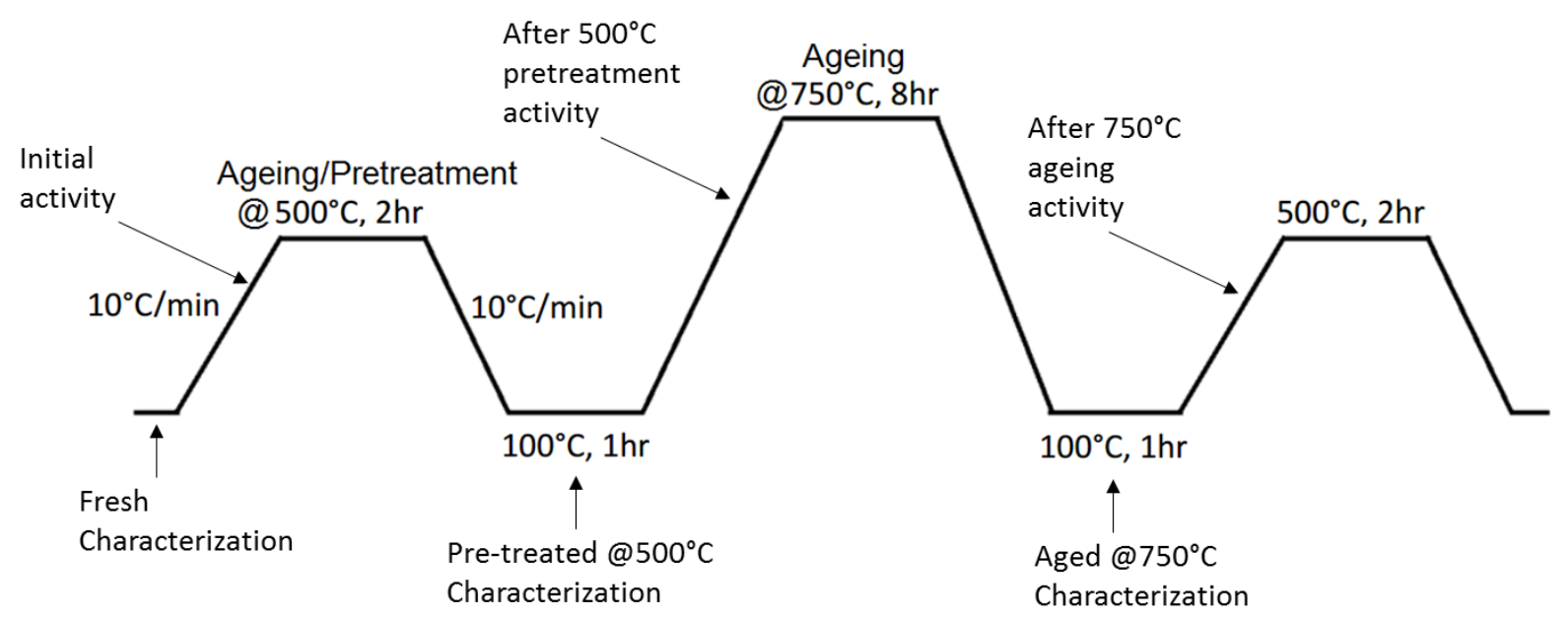

Figure 1. Temperature profile of the experimental setup. Ramp-up activities were measured at the indicated intervals. 


\section{a) Pt-only}

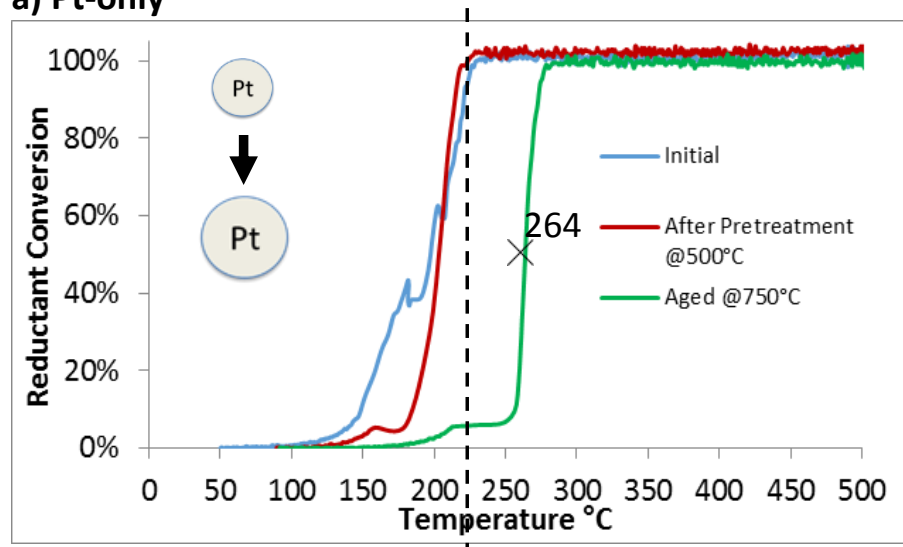

\section{b) Seq-SEA}

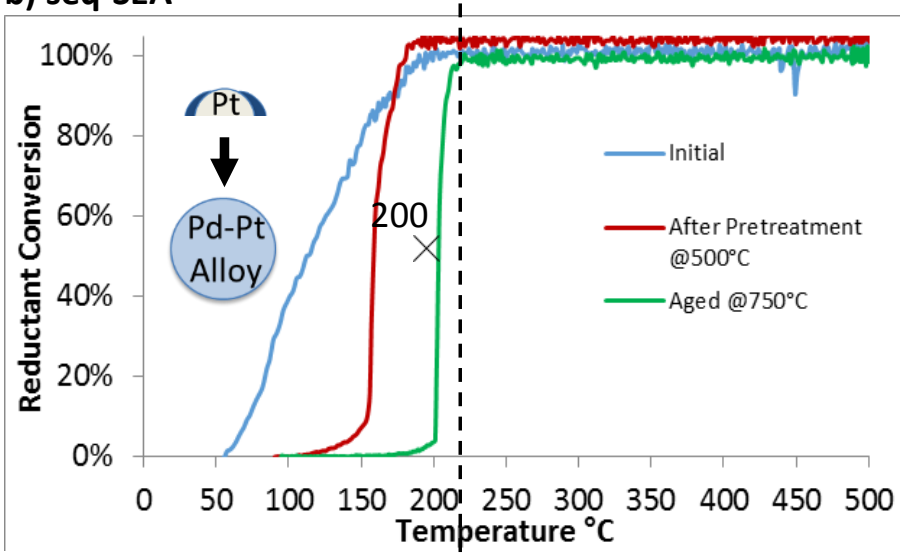

\section{c) co-DI}
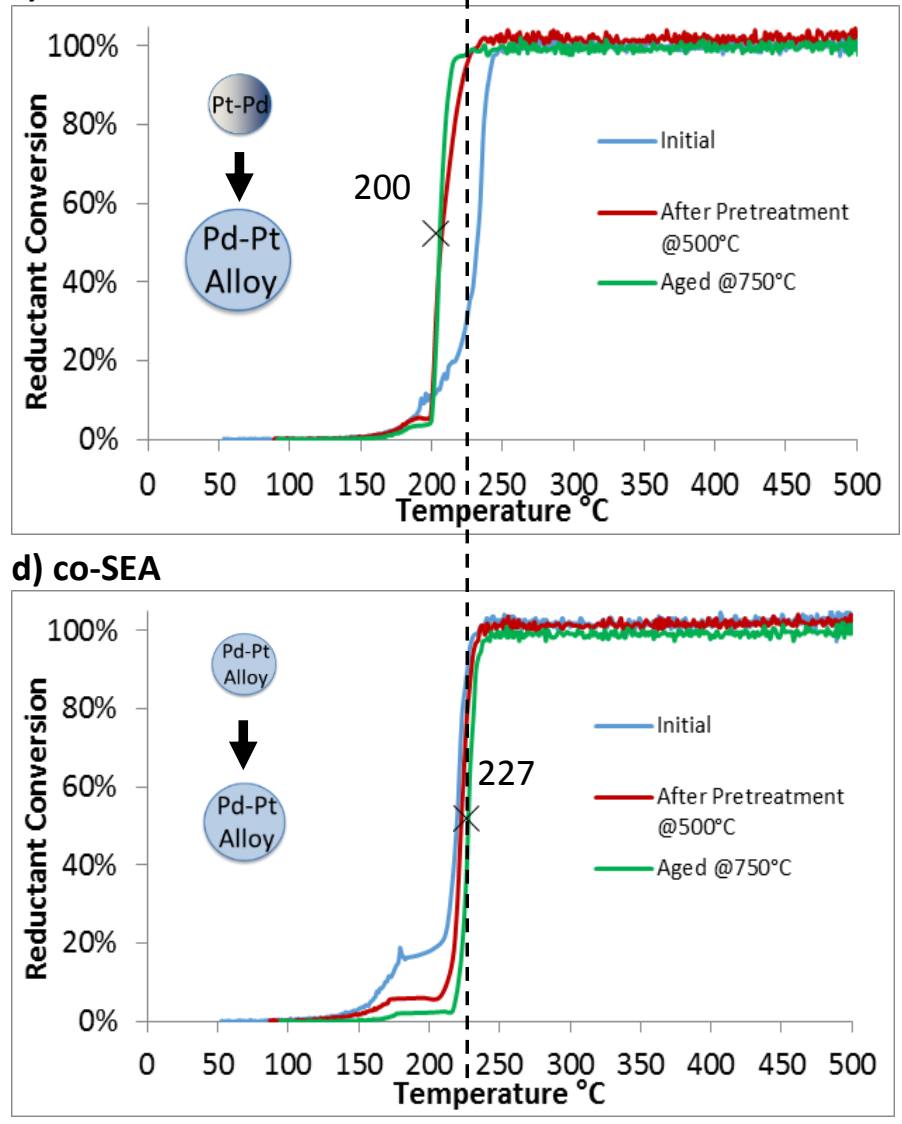

e) Pd-only

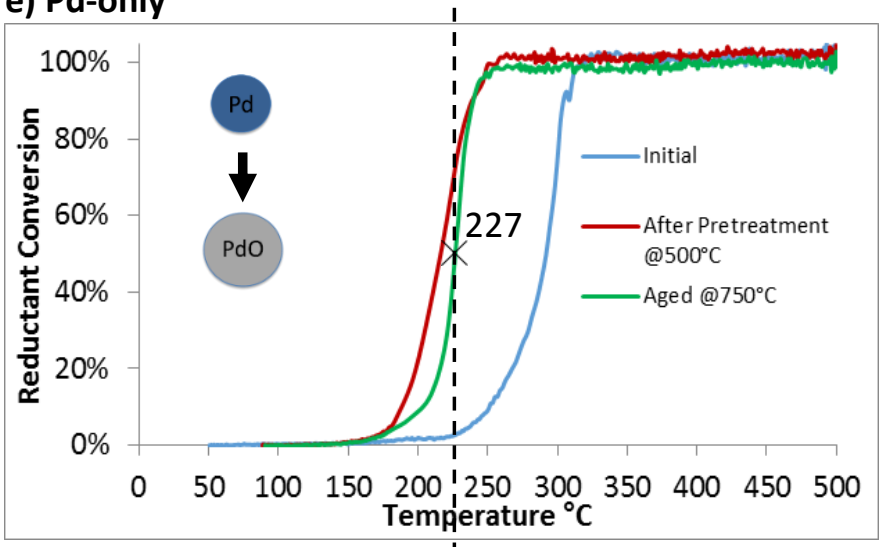

\section{f) seq-SEA}
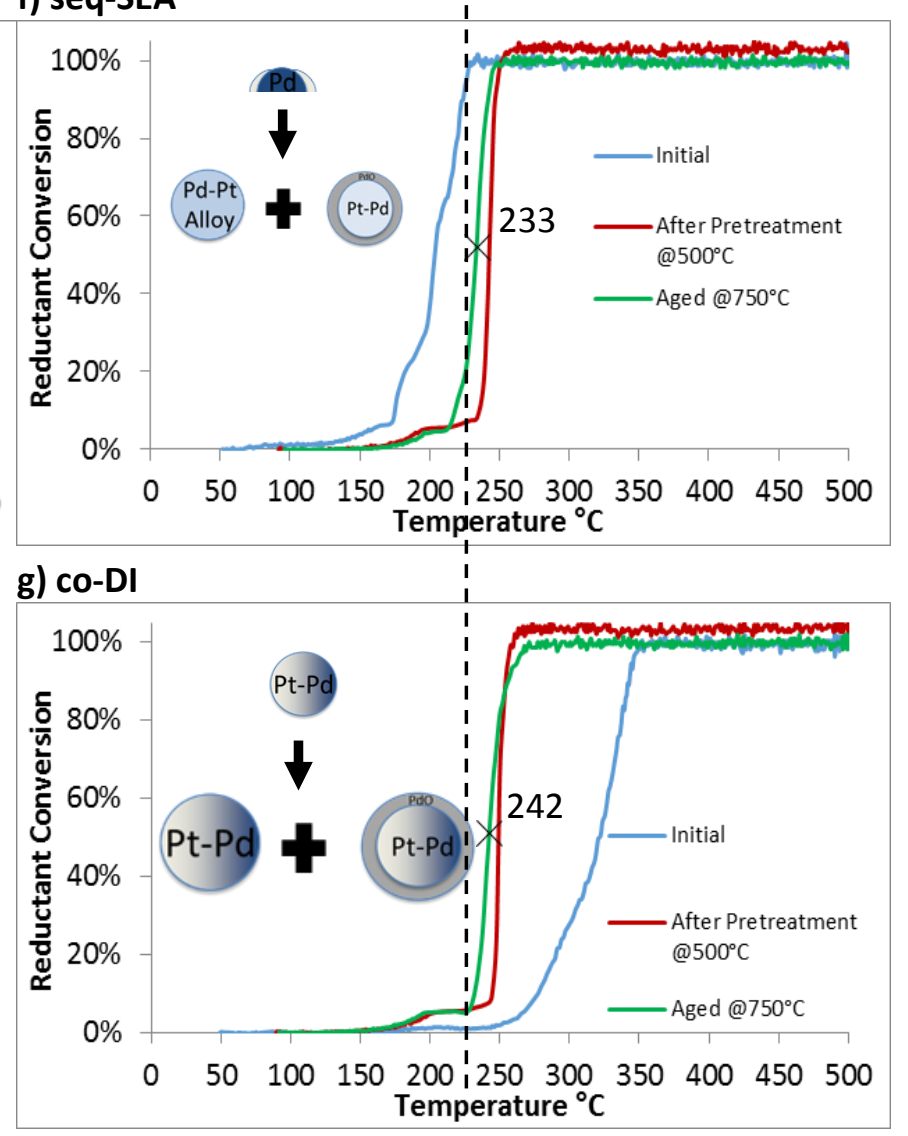

Figure 2. Light-off temperatures for the total reductants to $\mathrm{CO}_{2}$ for the alumina catalysts: a) 6.2Pt SEA, b) 6.0Pt/1.28Pd seq-SEA Pt@Pd, c) 6.0Pt/1.28Pd DI, d) 5.3Pt/1.58Pd co-SEA, e) 2.0Pd SEA, f) 2.0Pd/0.33Pt seqSEA Pd@Pt, g) 2.0Pd/0.33Pt DI. 
a) Pd-only
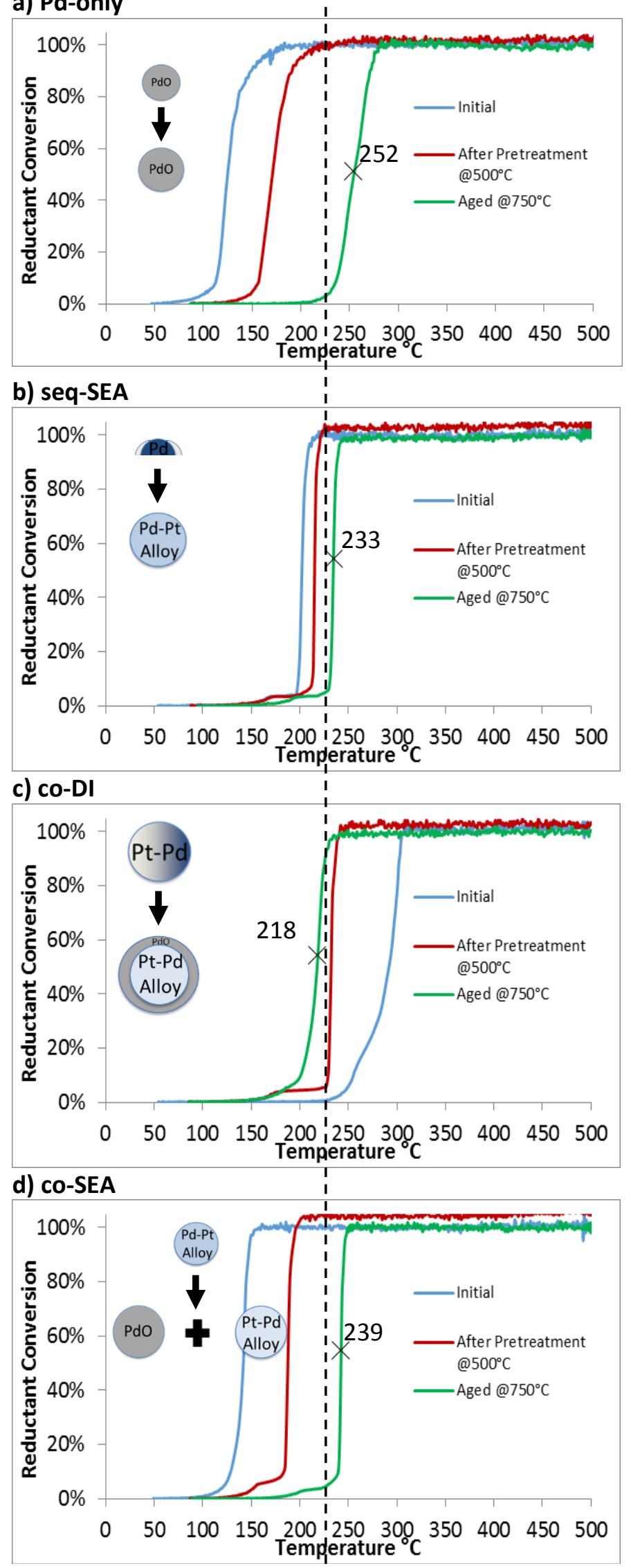

Figure 3. Light-off temperatures for the total reductants to $\mathrm{CO}_{2}$ for the Pd-rich silica catalysts: a) 4.OPd SEA, b) 4.0Pd/0.44Pt seq-SEA Pd@Pt, c) 4.0Pd/0.44Pt DI, d) 3.2Pd/0.56Pt co-SEA. Initial morphologies are depicted in the insets. 


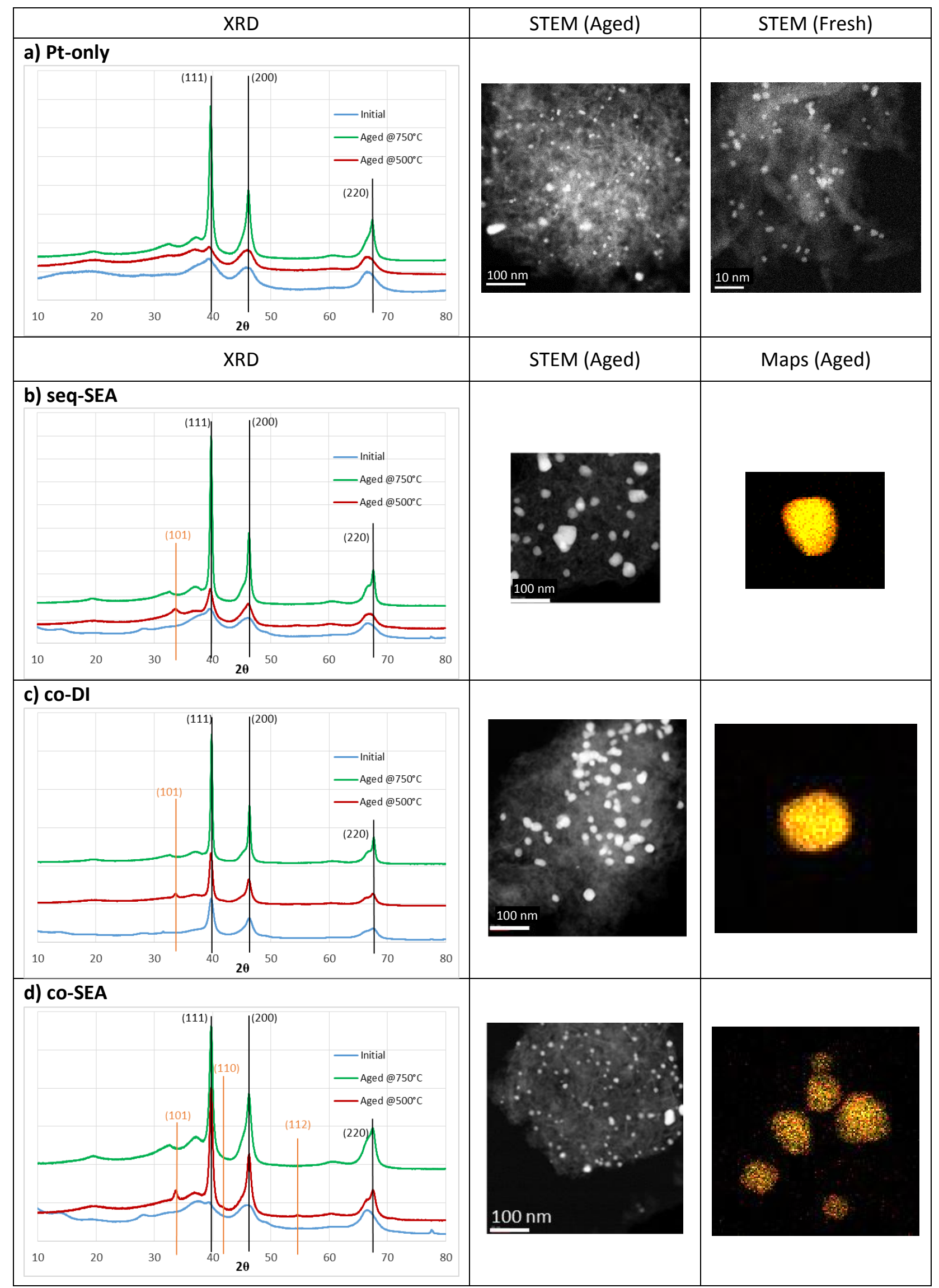

Figure 4. XRD patterns, STEM images, and elemental maps of Pt-rich alumina catalyst after hydrothermal aging. Elemental map colors are yellow for Pt and red for Pd. a) 6.2Pt SEA, b) 6.0Pt/1.28Pd seq-SEA Pt@Pd, c) 6.0Pt/1.28Pd DI, d) 5.3Pt/1.58Pd co-SEA 


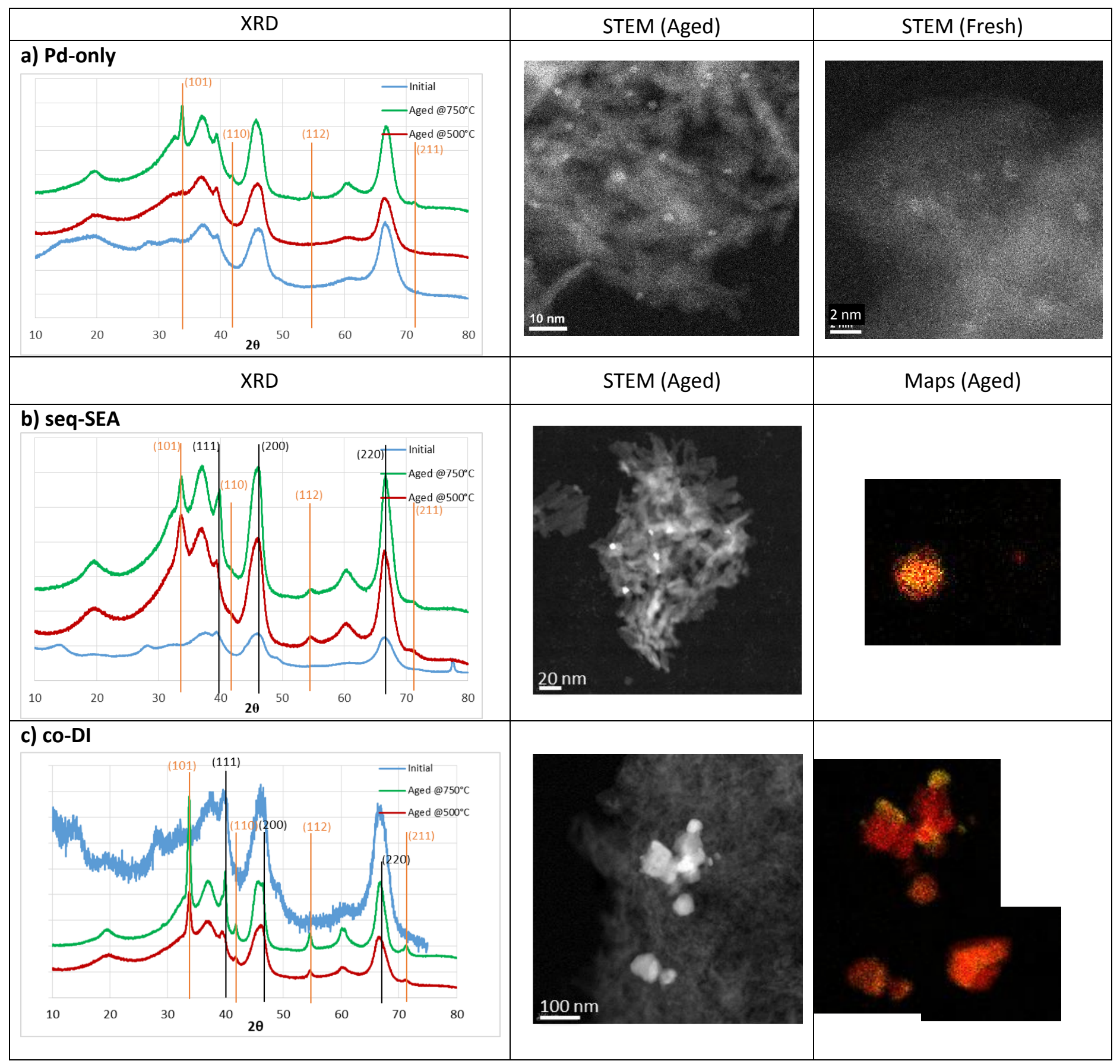

Figure 5. XRD patterns, STEM images, and elemental maps of Pd-rich alumina catalyst after hydrothermal aging. Elemental map colors are yellow for Pt and red for Pd. a) 2.0Pd SEA, b) 2.0Pd/0.33Pt seq-SEA Pd@Pt, c) 2.0Pd/0.33Pt DI 


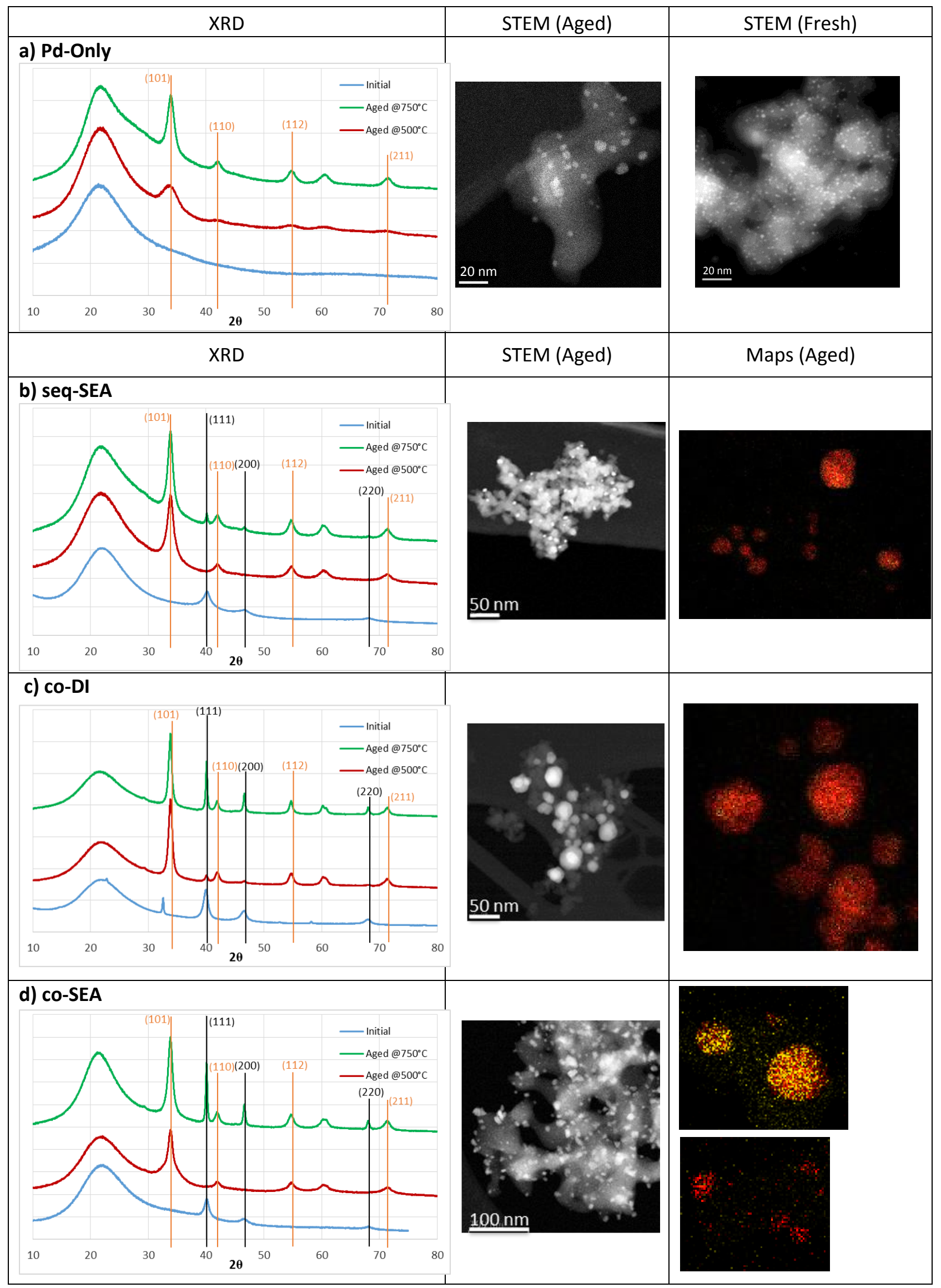

Figure 6. XRD patterns, STEM images, and elemental maps of Pd-rich silica catalyst after hydrothermal aging. Elemental map colors are yellow for Pt and red for $\mathrm{Pd}$. a) 4.0Pd SEA, b) 4.0Pd/0.44Pt seq-SEA Pd@Pt, c) 4.0Pd/0.44Pt DI, d) 3.2Pd/0.56Pt co-SEA 